\title{
USO DE DADOS METEOROLÓGICOS DE REANÁLISE PARA A SIMULACÃO DA VAZÃO NA BACIA HIDROGRÁFICA DO RIBEIRÃO DO PINHAL, LIMEIRAA/SP
}

\author{
João Carlos Batista Alves \\ Instituto Agronômico de Campinas - IAC \\ Centro de Solos e Recursos Ambientais, Campinas, SP, Brasil \\ joao cpf@terra.com.br \\ Letícia Lopes Martins \\ Instituto Agronômico de Campinas - IAC \\ Centro de Solos e Recursos Ambientais, Campinas, SP, Brasi \\ leticia.l.ufv@gmail.com \\ Wander Araújo Martins \\ Instituto Agronômico de Campinas - IAC \\ Centro de Solos e Recursos Ambientais, Campinas, SP, Brasil \\ wander.am.ufv@gmail.com \\ Jener Fernando Leite de Moraes \\ Instituto Agronômico de Campinas - IAC \\ Centro de Solos e Recursos Ambientais, Campinas, SP, Brasil \\ ifmoraes@iac.sp.gov.br
}

Gabriel Constantino Blain Instituto Agronômico de Campinas - IAC Centro de Ecofisiologia e Biofísica, Campinas, SP, Brasil gabriel@iac.sp.gov.br

\section{RESUMO}

A grande preocupação com a preservação dos recursos hídricos demanda estudos capazes de avaliar e mitigar os impactos decorrentes das ações antrópicas. O uso de modelos hidrológicos constitui-se numa ferramenta importante, pois permitem simular diferentes cenários e seus impactos na disponibilidade hídrica. No entanto, a complexidade de obter dados meteorológicos observados, torna necessária a utilizacão de outras fontes de dados. Objetivou-se avaliar se com a utilização de dados meteorológicos de reanálise obtidos do modelo Climate Forecast System Reanalysis (CFSR) é possível calibrar o modelo Soil and Water Assessment Tool (SWAT) e simular a produção de água numa bacia hidrográfica. A área de estudo é a bacia hidrográfica do Ribeirão do Pinhal (BHRP), situada no município de Limeira-SP. Utilizou-se o modelo SWAT para simulação hidrológica com os dados meteorológicos observados e de reanálise. Foi possível calibrar o modelo SWAT utilizando os dados meteorológicos observados e de reanálise. Porém, o ajuste foi melhor quando se utilizou os dados meteorológicos observados. A vazão simulada utilizando dados de reanálise foi superestimada. Os dados meteorológicos de reanálise são adequados para simulações hidrológicas com o modelo SWAT, o que é evidenciado por meio dos índices estatísticos satisfatórios obtidos no procedimento de calibração do modelo SWAT.

Palavras-chave: SWAT. Modelagem hidrológica. Calibração.

\section{USE OF REANALYSIS METEOROLOGICAL DATA FOR STREAMFLOW SIMULATION IN THE RIBEIRÃO DO PINHAL RIVER BASIN, LIMEIRA / STATE OF SÃO PAULO SP}

\begin{abstract}
The great concern with the preservation of water resources demands studies capable of evaluating and mitigating the impacts resulting from anthropic actions. Thus, the use of hydrological models becomes of great importance, as it allows to simulate different scenarios and impacts on water availability. However, the complexity of obtaining observed data makes the use of other data sources necessary. The aim of this paper is to evaluate whether the Soil and Water Assessment Tool (SWAT) model can be calibrated with the use of reanalysis meteorological data obtained from the Climate Forecast System Reanalysis (CFSR) model. The study area is the Ribeirão do Pinhal river basin (BHRP), located at Limeira-SP. The SWAT model was used for hydrological simulation with the observed meteorological data and reanalysis. It was possible to calibrate the SWAT model using the observed meteorological and reanalysis data. However, the adjustment was better when the observed meteorological data were used. Simulated flow using reanalysis data was overestimated. The reanalysis meteorological data are suitable for hydrological simulations
\end{abstract}


with the SWAT model, which is evidenced by the satisfactory statistical indices obtained in the SWAT model calibration procedure.

Keywords: SWAT. Hydrological modelling. Calibration.

\section{INTRODUÇÃO}

A crescente preocupação com a qualidade e disponibilidade hídrica torna mais intensa a necessidade de estudos e aplicação de práticas que atenuem esses problemas e garantam o abastecimento de água para gerações atuais e futuras. Problemas como a crise hídrica que acometeu o Brasil e, principalmente, o estado de São Paulo no ano de 2014, evidencia a essencialidade de tais pesquisas. Estudos referentes à qualidade e disponibilidade hídrica carecem de tempo e recursos, o que geralmente são escassos. Como alternativa pesquisadores de diversas regiões do globo têm utilizado ferramentas de modelagem hidrológica para a realização de estudos referentes à qualidade e disponibilidade hídrica em bacias hidrográficas (ARNOLD et al., 1998; NEITSCH et al., 2011; PEREIRA et al., 2016; PAZ et al., 2018).

Modelos hidrológicos são recursos computacionais utilizados para modelar fenômenos que ocorrem em uma unidade da paisagem, normalmente bacias hidrográficas (TUCCI, 1997). Por meio de equações matemáticas e recursos computacionais, são capazes de representar matemática e espacialmente os fenômenos ocorridos no ciclo hidrológico de uma bacia hidrográfica (RENNÓ e SOARES, 2000). Além disso, torna-se possível, por meio dos modelos, simular diferentes cenários de uso e ocupação do solo, por exemplo, a fim de prever o impacto de uma determinada tomada de decisão antes dessa ser implementada na bacia hidrográfica (BLAINSKI; ACOSTA; NOGUEIRA, 2017). Dentre os modelos hidrológicos existentes o modelo Soil and Water Assessment Tool (SWAT) tem se destacado por sua ampla utilização em todo o mundo (GASSMAN et al., 2007; ANDRADE; MELO; BESKOW, 2013; BRESSIANI et al., 2015; ABBASPOUR et al., 2015). O SWAT é um software de domínio público desenvolvido pelo Agricultural Research Service of the United States Departament of Agricultural (ARS-USDA), com o objetivo de avaliar o impacto de alterações no uso do solo sobre os recursos hídricos. Por meio do SWAT é possível realizar simulações hidrológicas e inferências sobre vegetação, clima, manejo e uso da terra, pesticidas, sedimentos, nutrientes e outros.

No entanto, para a realização da modelagem hidrológica e posterior obtenção de resultados satisfatórios, é necessário fornecer dados meteorológicos ao modelo. Em geral, encontram-se problemas relacionados às estações meteorológicas como, elevado percentual de falhas ou dados inexistentes (MONTEIRO et al., 2015; BRIGHENTI; BONUMÁ; CHAFFE, 2016; PAZ et al., 2018). Outro entrave para a realização de modelagem hidrológica no Brasil é a dificuldade de obtenção de variáveis climáticas comumente não medidas como, radiação solar, umidade relativa do ar e velocidade do vento. Nesse contexto, a utilização de fontes alternativas de dados meteorológicos torna-se uma opção para contornar a ausência desses dados e, assim, possibilitar a realização da modelagem hidrológica (MONTEIRO et al., 2015).

Os dados meteorológicos de reanálise são obtidos por meio da assimilação e reanálise de dados observados em superfície (estações meteorológicas), aviões, navios, imagens de satélite, imagens de radar e radiossondagem de todo o planeta (MONTEIRO et al., 2015; MICALISCHEN, 2018). Existem diferentes fontes de dados de reanálise, no entanto os desenvolvedores do modelo SWAT indicam a utilização dos dados meteorológicos de reanálise obtidos a partir do modelo Climate Forecast System Reanalysis (CFSR). O modelo CFSR disponibiliza dados meteorológicos de alta resolução $(38 \mathrm{Km})$ e apresentam uma série de dados diários correspondente ao período de 36 anos (1979 a 2014). A utilização de dados meteorológicos de reanálise é uma alternativa interessante para a realização de estudos de modelagem hidrológica, porém é necessário identificar se esses dados são representativos das características climáticas da região em estudo. Nesse sentido, o objetivo do presente trabalho foi avaliar se com a utilização de dados meteorológicos de reanálise é possível calibrar o modelo hidrológico SWAT e, posteriormente, utilizá-lo como ferramenta de simulação hidrológica e de planejamento agroambiental. 


\section{METODOLOGIA}

\section{LOCALIZAÇÃO DA ÁREA DE ESTUDO}

A área de estudo é a bacia hidrográfica do Ribeirão do Pinhal (BHRP), situada nos municípios de Limeira, Cordeirópolis, Engenheiro Coelho e Arthur Nogueira, estado de São Paulo, entre as coordenadas $22^{\circ} 40^{\prime} 43,31^{\prime \prime}$ e $22^{\circ} 24^{\prime} 41,00^{\prime \prime} \mathrm{S}$ e $47^{\circ} 25^{\prime} 59,60^{\prime \prime}$ e $47^{\circ} 11^{\prime} 08,79^{\prime \prime} \mathrm{O}$ e altitude média de $570 \mathrm{~m}$ (Figura 1).

Figura 1 - Unidade de Gerenciamento de Recursos Hídricos 5 (UGRHI 5), localização geográfica, limites e hidrografia da Bacia Hidrográfica do Ribeirão do Pinhal (BHRP).<smiles>CC(N)(SC(N)(N)F)C(=O)O</smiles>

$$
\text { América do Sul (Brasil) }
$$

Estado de São Paulo

(UGRHI 05)
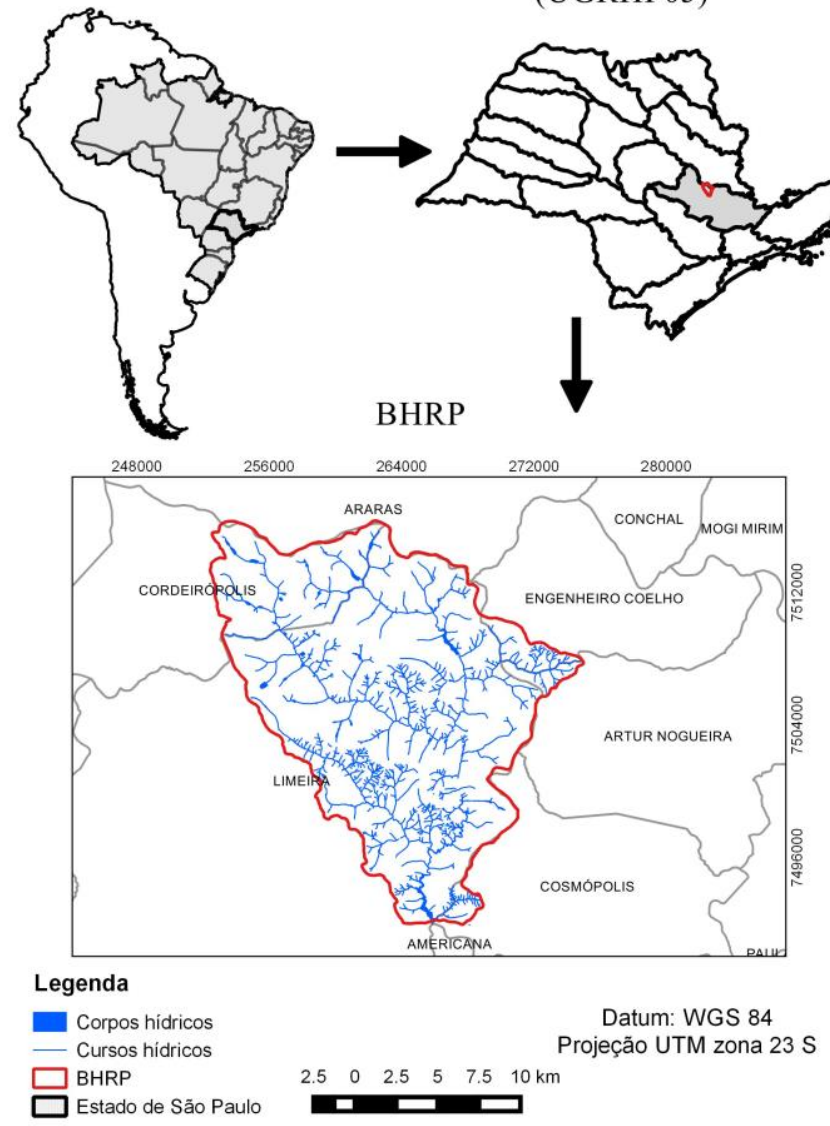

Fonte - Elaborado pelos autores.

A bacia hidrográfica do Ribeirão do Pinhal está inserida na Unidade de Gerenciamento de Recursos Hídricos número cinco (UGRHI 5), a qual é composta por 60 municípios, que atendem à demanda de uma população de 4.991 .762 habitantes, além da demanda industrial e agrícola. Além disso, situa-se em uma das regiões mais críticas do estado de São Paulo no tocante à disponibilidade hídrica. Nesta UGRHI o uso da água ocorre, principalmente, para o abastecimento da população, uso industrial e rural (LIMEIRA, 2017). Em virtude da localização e importância econômica dessa região o uso e 
gestão da água são de fundamental importância a fim de garantir a disponibilidade desse recurso em quantidade e qualidade adequada a todos os setores.

A BHRP está inserida na Depressão do Médio Tietê, que por sua vez está contida na Depressão Periférica Paulista, a qual possui topografia suave ondulada, e integra a Bacia Sedimentar do Paraná. É constituiída por rochas pertencentes à Formação Tatuí, Itararé, Irati e Serra Geral (CPRM 2006). Segundo o "Diagnóstico Agroambiental da bacia do Ribeirão do Pinhal" (MORAES et al., 2009), os solos que ocorrem na BHRP, de acordo com a classificação proposta por Santos et al. (2013), pertencem às seguintes ordens: Argissolos, Cambissolos, Gleissolos, Latossolos, Neossolos e Nitossolos.

A vegetação original da BHRP constitui-se por Savana (cerrado) e Floresta Estacional Semidecidual (IBGE 2012), no entanto vem sendo suprimida em decorrência do crescimento das cidades e expansão agrícola. O clima da região em que a BHRP está localizada é classificado, como Cwa, tropical chuvoso, segundo a classificação climática de Köppen (ALVARES et al. 2013), a temperatura média anual varia de $18,1^{\circ} \mathrm{C}$ a $24,6^{\circ} \mathrm{C}$ com precipitação anual de $1336 \mathrm{~mm}$ (MORAES et al., 2009).

A BHRP caracteriza-se, predominantemente, pelo uso agrícola, com destaque para a atividade canavieira e citricultura (MORAES et al. 2009; ROCHA 2015). As áreas ocupadas com cultivo de cana-de-açúcar correspondem a 47,86\%, a atividade citrícola representa 12,77\%, 9,49\% com floresta nativa, $7 \%$ com macega, $5 \%$ com pastagem, $3 \%$ com solo exposto, 3,5\% com culturas anuais e horticultura, $7,7 \%$ com usos urbanos (usos residenciais e vias de transporte urbano).

\section{MODELAGEM HIDROLÓGICA}

Utilizou-se o modelo SWAT para simular os cenários de hidrologia com à utilização dos dados meteorológicos observados e de reanálise. O SWAT foi desenvolvido pelo Agricultural Research and Texas A\&M University (USDA) na década de 1990 com o objetivo de detectar a influência das mudanças no uso e cobertura da terra no ciclo hidrológico. Para isso o modelo é dividido em sete componentes principais: hidrologia, clima, sedimentos, crescimento vegetal, manejo agrícola, nutrientes e pesticidas (ARNOLD et al., 1998).

O SWAT simula o ciclo hidrológico por meio da divisão deste em duas fases: a fase terrestre e a fase de propagação (ARNOLD et al., 1998). A fase terrestre é a responsável pelo controle da quantidade de água, nutrientes, sedimentos e descarga de agroquímicos no interior do canal principal de cada sub-bacia (NEITSCH et al., 2011). A fase de propagação é a responsável pela propagação, propriamente dita, do fluxo de água, sedimentos, nutrientes e agroquímicos pela rede hidrográfica da bacia até o local de descarga (exutório da bacia) (NEITSCH et al., 2011). O SWAT utiliza a equação do balanço hídrico para modelar o comportamento hidrológico (1):

$\mathrm{SWt}=\mathrm{SW}_{0}+\sum_{\mathrm{i}=1}^{\mathrm{t}}\left(\mathrm{R}_{\mathrm{day}}-\mathrm{Q}_{\text {surf }}-\mathrm{E}_{\mathrm{a}}-\mathrm{W}_{\text {seep }}-\mathrm{Q}_{\mathrm{gw}}\right)$

em que: SWt é a quantidade final de água no solo $\left(\mathrm{mm} \mathrm{H}_{2} \mathrm{O}\right)$; $\mathrm{SW}_{0}$ é a quantidade inicial de água no solo no dia i ( $\left.\mathrm{mm} \mathrm{H}_{2} \mathrm{O}\right)$; t é o tempo (dias); Rday é a precipitação total diária no dia i $(\mathrm{mm})$; $Q_{\text {surf é o }}$ escoamento total diário no dia i $(\mathrm{mm})$; $\mathrm{E}_{\mathrm{a}}$ é a evaporação total diária no dia i; $\mathrm{W}_{\text {seep é a quantidade de }}$ água que entra na zona de aeração do perfil do solo no dia i $(\mathrm{mm})$; Qgw é a vazão de retorno no dia i $(\mathrm{mm})$.

Para a realização das simulações hidrológicas o modelo SWAT divide a bacia hidrográfica em subbacias a partir do modelo digital de elevação (MDE) e rede hidrográfica. Após a criação das subbacias, o modelo requer informações referentes ao tipo de solo, uso da terra e declividade, essas informações são necessárias para a discretização espacial da bacia hidrográfica em unidades 
homogêneas quanto ao uso, solo e declividade, denominadas de Hydrologic Response Units (HRUs) (NEITSCH et al., 2011). A criação das HRUs pelo modelo melhora a acurácia dos resultados obtidos por meio das simulações. Além de possibilitar a avaliação dos cenários propostos por tipo de uso do solo (ARNOLD et al., 1998).

\section{BASE DE DADOS}

Para a realização da simulação hidrológica por meio do modelo SWAT são necessários os seguintes dados de entrada: modelo digital de elevação, mapa pedológico, mapa de uso e ocupação das terras e dados meteorológicos (precipitação pluvial, temperatura máxima e mínima do ar, velocidade do vento, umidade relativa do ar e radiação solar) (NEITSCH et al., 2011). Na realização da modelagem hidrológica a disponibilidade e qualidade dos dados são de fundamental importância para a representatividade e confiabilidade dos resultados obtidos (ARNOLD et al., 1998; MORIASI et al., 2007; NEITSCH et al., 2011). Destaca-se que as informações supracitadas são as mínimas requeridas para a realização da modelagem hidrológica, havendo mais informações edafoclimáticas, de uso e manejo das terras, adubação entre outras, as mesmas podem ser inseridas no modelo, aumentando a acurácia das predições realizadas (ARNOLD et al., 1998; ARNOLD et al., 2012).

O modelo digital de elevação (MDE) foi confeccionado a partir da hidrografia e das curvas de nível em escala de 1:10.000 (provenientes do "Instituto Geográfico e Cartográfico do estado de São Paulo "IGC-SP"), com equidistância vertical de 5 metros. O levantamento pedológico da BHRP foi realizado em escala 1:50.000. As seguintes classes de solos foram determiandas: CAMBISSOLO HÁPLICO tb Distrófico (CXd), GLEISSOLO HÁPLICO tb Eutrófico típico (GXd), LATOSSOLO VERMELHOAMARELO Distrófico típico A moderado, textura média (LVAd), LATOSSOLO VERMELHOAMARELO Distrófico típico A moderado, textura argilosa (LVAd12), LATOSSOLO VERMELHOAMARELO Distrófico Argissólico (LVAPV), LATOSSOLO VERMELHO Distroférrico típico (LVdf), NITOSSOLO VERMELHO Distroférrico típico (NVdf), ARGISSOLO VERMELHO-AMARELO Distrófico típico (PVA), NEOSSOLO LITÓLICO Distrófico típico (RLd). O MDE e o mapa pedológico foram confeccionados anteriormente em um levantamento agroambiental (Diagnóstico Agroambiental da bacia do Ribeirão do Pinhal) de autoria de MORAES et al., (2009).

O mapa de uso da terra com imagens correspondentes ao ano de 2016 foi obtido em um estudo de calibração do modelo SWAT para a BHRP realizado anteriormente (MARTINS et al., 2020). As classes de uso do solo que ocorrem na BHRP (com a codificação do SWAT) são as seguintes: agricultura genérica (AGRL), solo exposto (BSVG), cultura anual (CORN), reflorestamento (EUCA), floresta nativa (FRSE), horticultura (LETT), citricultura (ORAN), pastagem (PAST), macega (RNGB), cana-de-açúcar (SUGC), urbano alta-densidade (URHD), urbano baixa-densidade (URLD), vias urbanas (UTRN), cursos e corpos hídricos (WATR), várzeas (WETL).

As seguintes classes de declividade foram consideradas: 0-3\%, 3-6\%, 6-9\%, 9-12\%, 12-25\% e maior que $25 \%$, conforme proposto por LEPSCH et al. (1983). Destaca-se que, os mapas de uso do solo e pedológico, bem como o MDE, apresentam resolução espacial de $30 \times 30$ metros. O MDE, mapa pedológico, mapa de uso e ocupação do solo são apresentados na figura 2. A distribuição relativa de cada classe de solo, uso da terra e faixa de declividade na BHRP são apresentadas na Tabela 1. A fim de melhorar a acurácia da simulação hidrológica alguns parâmetros tiveram os seus valores iniciais alterados. Os fatores $\mathrm{C}$ e $\mathrm{P}$ da Equação Universal de Perda de Solo (EUPS) e a curva-número (CN) foram modificados conforme proposto por MARTINS et al. (2020). Vale ressaltar que, os 
parâmetros físico-hídricos de cada classe de solo foram obtidos por meio do projeto "Diagnóstico Agroambiental da bacia do Ribeirão do Pinhal" (MORAES et al., 2009).

Figura 2 - MDE e mapas necessários para a realização da simulação hidrológica com o SWAT. a) Modelo Digital de Elevação; b) Mapa pedológico; c) Mapa de uso das terras.

a)
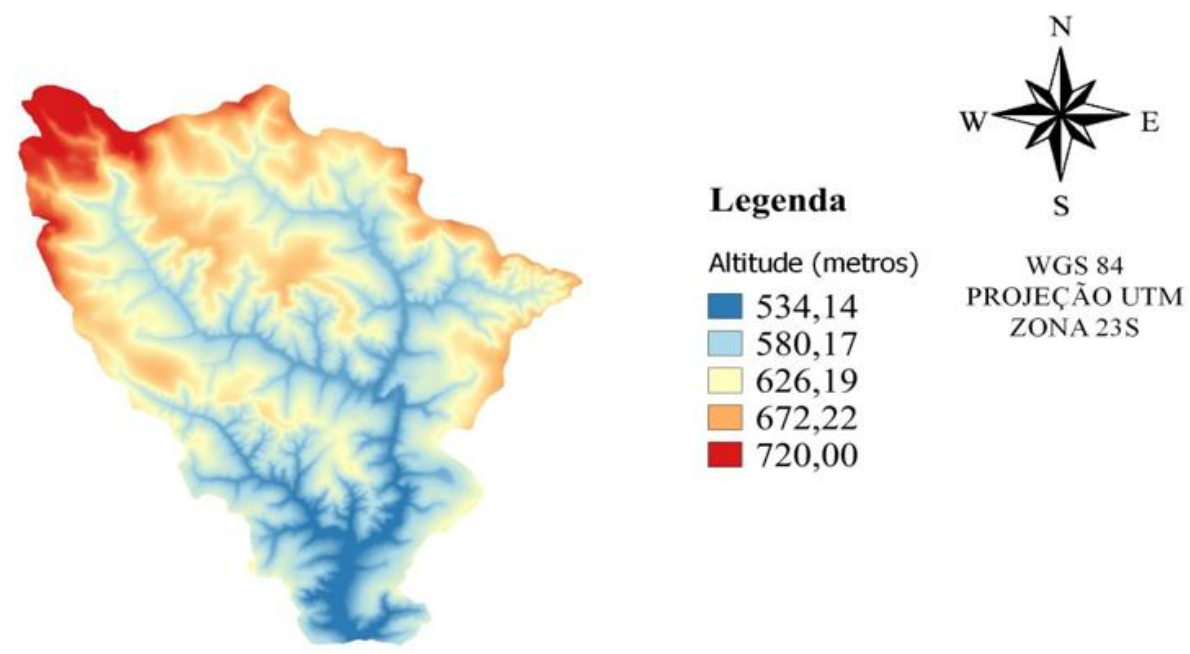

b)

c)
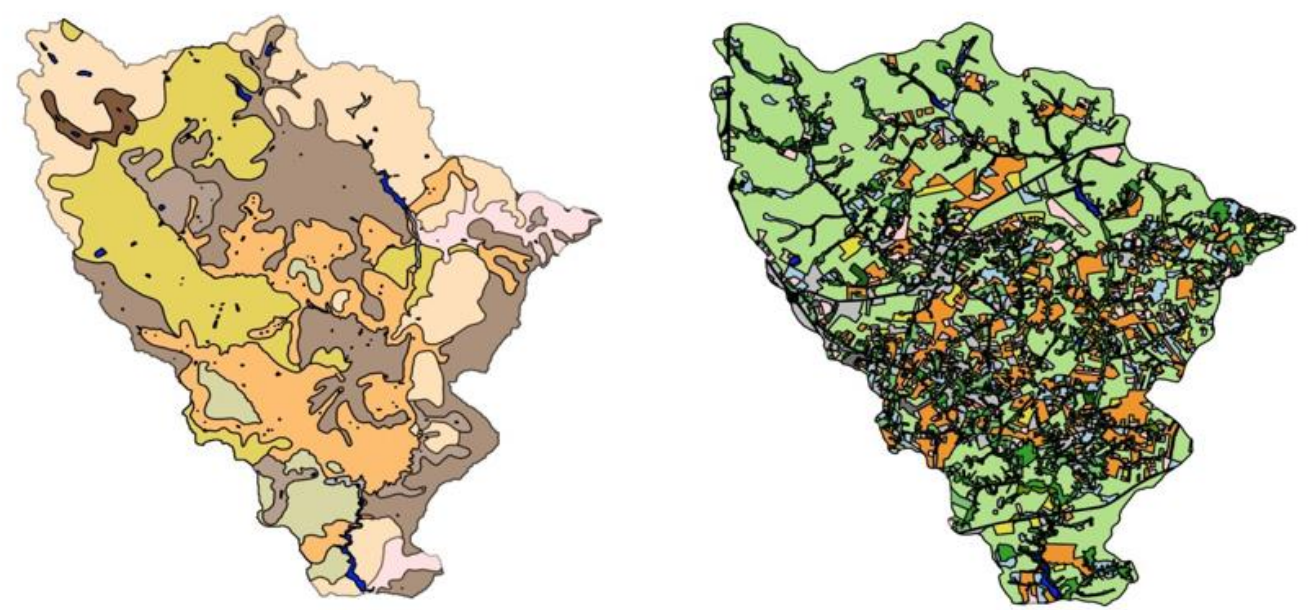

Legenda

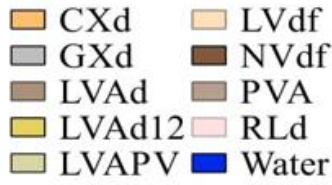

Legenda

$\square$ AGRL $\square$ LETT $\square$ URHD
$\square$ BSVG $\square$ ORAN $\square$ URLD
$\square$ CORN $\square$ PAST $\square$ UTRN
$\square$ EUCA $\square$ RNGB $\square$ WATR
$\square$ FRSE $\square$ SUGC $\square$ WETL

Legenda - AGRL: agricultura genérica; BSVG: solo exposto; CORN: cultura anual; EUCA: reflorestamento; FRSE: floresta nativa; LETT: horticultura; ORAN: citricultura; PAST: pastagem; RNGB: macega; SUGC: cana-deaçúcar; URHD: urbano alta-densidade; URLD: urbano baixa-densidade; UTRN: vias urbanas; WATR: cursos hídricos; WETL: várzeas. A descrição das siglas do mapa pedológico encontra-se na tabela 1. Fonte - Elaborado pelos autores. 
Tabela 1 - Distribuição relativa do uso da terra, classes de solos e declividade na BHRP.

\begin{tabular}{|c|c|c|c|}
\hline & Sigla SWAT & Área (ha) & Área (\%) \\
\hline \multirow{15}{*}{ Uso da terra } & SUGC & $14.050,61$ & 47,86 \\
\hline & ORAN & $3.748,08$ & 12,77 \\
\hline & FRSE & $2.786,07$ & 9,49 \\
\hline & RNGB & $2.078,76$ & 7,08 \\
\hline & URLD & $2.036,43$ & 6,94 \\
\hline & PAST & $1.519,13$ & 5,17 \\
\hline & BSVG & $1.117,49$ & 3,81 \\
\hline & CORN & 745,94 & 2,54 \\
\hline & WETL & 430,86 & 1,47 \\
\hline & AGRL & 249,15 & 0,85 \\
\hline & WATR & 202,38 & 0,69 \\
\hline & UTRN & 157,69 & 0,54 \\
\hline & EUCA & 124,05 & 0,42 \\
\hline & URHD & 85,13 & 0,29 \\
\hline & LETT & 26,25 & 0,09 \\
\hline \multirow{9}{*}{ Solos } & ${ }^{1}$ LVAd & $6.957,79$ & 23,70 \\
\hline & ${ }^{2} \mathrm{LVdf}$ & $6.722,11$ & 22,90 \\
\hline & ${ }^{3} \mathrm{CXd}$ & $5.764,31$ & 19,63 \\
\hline & ${ }^{4}$ LVAd12 & $5.728,52$ & 19,51 \\
\hline & ${ }^{5}$ LVAPV & $1.343,15$ & 4,58 \\
\hline & ${ }^{6} \mathrm{PVA}$ & $1.286,61$ & 4,38 \\
\hline & ${ }^{7} \mathrm{RLd}$ & 865,41 & 2,95 \\
\hline & ${ }^{8} \mathrm{NVdf}$ & 346,18 & 1,18 \\
\hline & ${ }^{9} \mathrm{GXd}$ & 113,78 & 0,39 \\
\hline \multirow{6}{*}{ Declividade } & $3-6 \%$ & $8.500,76$ & 28,96 \\
\hline & $6-9 \%$ & $6.700,18$ & 22,82 \\
\hline & $0-3 \%$ & $5.169,98$ & 17,61 \\
\hline & $12-25 \%$ & $4.477,92$ & 15,25 \\
\hline & $9-12 \%$ & $4.088,82$ & 13,93 \\
\hline & $>25 \%$ & 420,38 & 1,43 \\
\hline
\end{tabular}

${ }^{*}$ LLVAd (Latossolo Vermelho-Amarelo Distrófico típico, A moderado, textura média); ${ }^{2}$ LVdf (Latossolo Vermelho Distroférrico e Eutroférrico típico, textura muito argilosa e argilosa); ${ }^{3} \mathrm{CXd}$ (Associação de Cambissolo Háplico Tb Distrófico e Tb Eutrófico, textura média e média/argilosa + Neossolo Litólico Distrófico e Eutrófico, textura média, ambos típicos); ${ }^{4}$ LVAd12 (Latossolo Vermelho-Amarelo Distrófico típico, A moderado, textura argilosa ou muito argilosa); ${ }^{5}$ PVA (Argissolo Vermelho-Amarelo Distrófico típico, textura arenosa/média; Argissolo VermelhoAmarelo Distrófico típico, textura média/argilosa; Argissolo Vermelho-Amarelo Eutrófico típico e arênico, textura

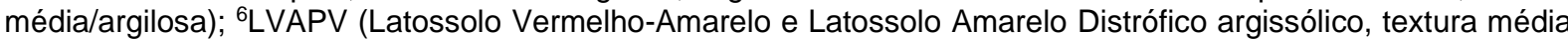
e arenosa/média); ${ }^{7}$ RLd (Associação de Neossolo Litólico Distrófico, textura média, + Cambissolo Háplico Tb Distrófico, textura média/argilosa); ${ }^{8} \mathrm{NVdf}$ (Nitossolo Vermelho Distroférrico e Eutroférrico típico, textura muito argilosa); ${ }^{9} \mathrm{GXd}$ (Complexo de Gleissolo Háplico Tb Eutrófico + Cambissolo Flúvico Tb Eutrófico e Distrófico gleissólico + Neossolo Flúvico Tb eutrófico e Tb Distrófico, textura indiscriminada).

As informações meteorológicas (precipitação pluvial e temperatura máxima e mínima do ar) foram obtidas de duas bases de dados diferentes, sendo elas: Centro Integrado de Informações Agrometeorológicas (IAC/CIIAGRO) - dados meteorológicos observados - e CFSR (dados meteorológicos de reanálise). Os dados meteorológicos observados e de reanálise são correspondentes a uma série histórica de dados em escala diária referente ao período de 2004 a 2013, para as variáveis precipitação pluvial e temperaturas máxima e mínimas do ar. Os dados meteorológicos observados foram obtidos de duas estações meteorológicas localizadas nos 
munícipios de Cordeirópolis $\left(22^{\circ} 27^{\prime} 32,99^{\prime \prime} \mathrm{S}\right.$ e $\left.47.24^{\prime} 25,95^{\prime \prime} \mathrm{O}\right)$ e Nova Odessa $\left(22^{\circ} 46^{\prime} 16,19^{\prime \prime} \mathrm{S}\right.$ e $47^{\circ} 18^{\prime} 13,68^{\prime \prime}$ O), ambos no estado de São Paulo.

Os dados meteorológicos de reanálise foram estimados pelo programa CFSR, os quais correspondem ao período de 2004 a 2013, uma série completa de dados diários e sem falhas, que possui resolução de $38 \mathrm{Km}\left(0,3125^{\circ}\right)$ e cobertura global. Na plataforma CFSR foram selecionados quatro pontos nas proximidades da região analisada, sendo que estes correspondem às estações meteorológicas com os dados de reanálise (Tabela 2).

Tabela 2 - Localização das estações meteorológicas do CFRS (dados de reanálise).

\begin{tabular}{cccc}
\hline Estação & Latitude & Longitude & Período \\
\hline p- 226-475 & $22^{\circ} 38^{\prime} 13,20^{\prime \prime} \mathrm{S}$ & $47^{\circ} 30^{\prime} \mathrm{O}$ & $2004-2013$ \\
$\mathrm{p}-223-475$ & $22^{\circ} 19^{\prime} 26,40^{\prime \prime} \mathrm{S}$ & $47^{\circ} 30^{\prime} \mathrm{O}$ & $2004-2013$ \\
$\mathrm{p}-226-472$ & $22^{\circ} 38^{\prime} 13,20^{\prime \prime} \mathrm{S}$ & $47^{\circ} 11^{\prime} 16,80^{\prime \prime} \mathrm{O}$ & $2004-2013$ \\
$\mathrm{p}-223-472$ & $22^{\circ} 19^{\prime} 26,40^{\prime \prime} \mathrm{S}$ & $47^{\circ} 11^{\prime} 16,80^{\prime \prime} \mathrm{O}$ & $2004-2013$ \\
\hline
\end{tabular}

Fonte - Global Weather (2019).

Os dados referentes à vazão, necessários para o procedimento de calibração hidrológica do modelo, foram disponibilizados pela empresa Salto do Lobo Companhia Energética. Esses dados são correspondentes ao período de 2012 e 2013 (dados mensais) e foram obtidos do posto fluviométrico localizado nas seguintes coordenadas $22^{\circ} 37^{\prime} 26,04^{\prime \prime} \mathrm{S}$ e $47^{\circ} 16^{\prime} 30,00^{\prime \prime} \mathrm{O}$. Destaca-se que pelo fato de haver duas fontes de dados meteorológicos (dados meteorológicos observados e dados meteorológicos de reanálise), foram realizados dois procedimentos de calibração hidrológica. A calibração hidrológica com os dados meteorológicos observados foi realizada previamente por Martins et al. (2020). No entanto, no presente trabalho, realizou-se a calibração hidrológica com os dados meteorológicos de reanálise, a partir dos dados de vazão disponibilizados pela empresa Salto do Lobo.

\section{ANÁLISES ESTATÍSTICAS DOS DADOS METEOROLÓGICOS}

Anteriormente à realização do processo de modelagem hidrológica realizou-se análise estatística dos dados meteorológicos observados e de reanálise a fim de verificar a qualidade dos mesmos e realizar a comparação entre as duas fontes de dados. Para a realização das análises estatísticas considerouse os seguintes parâmetros: coeficiente de determinação $\left(R^{2}\right)$, coeficiente de correlação de Pearson (r), erro quadrático médio, erro médio absoluto, índice de Willmott modificado (d), índice estatístico de Nash e Sutcliffe (NS) e percentual de viés (PBIAS). A existência de relação funcional entre variáveis dependentes e independentes foi verificada por meio do $R^{2}$ (PETERNELLI, 2004), o grau de correlação entre as variáveis foi determinado pelo coeficiente de correlação de Pearson (MUKAKA, 2012). As diferenças entre os valores simulados pelo modelo CFRS (ou de reanálises) e os observados, foram verificadas por meio do erro quadrático médio (LEGATES e MCCABE Jr.,1999). O valor absoluto da diferença entre os valores simulados pelo modelo CFRS (ou de reanálise) e os observados foi determinado pelo erro médio absoluto (LEGATES e MCCABE Jr.,1999). O índice de Willmot modificado foi utilizado para avaliar o desempenho do modelo (aproximação dos dados de reanálise aos dados observados) (PEREIRA et al., 2018). O índice estatístico de Nash e Sutcliffe (NS) e o PBIAS foram utilizados para avaliar o desempenho do modelo. O NS foi utilizado para avaliar o ajuste dos dados de vazão simulados (com os dados meteorológicos de reanálise) aos observados, enquanto que o PBIAS foi utilizado para determinar a tendência de sub ou superestimação dos dados de vazão simulados com dados meteorológicos de reanálise em relação aos dados de vazão observados (MORIASI et al., 2007).

\section{CENÁRIOS}

Foram considerados dois cenários para a realização da modelagem hidrológica, dados observados e dados de reanálise. Os cenários diferem quanto à origem dos dados meteorológicos, as demais informações permaneceram inalteradas. Deste modo, foi possível avaliar a representatividade e acurácia das diferentes fontes de dados meteorológicos nas simulações hidrológicas. 


\section{SIMULAÇÃO HIDROLÓGICA}

Para a realização da simulação hidrológica procedeu-se com as seguintes etapas:

- Inserção dos dados no modelo: a partir da inserção do MDE e a definição do detalhamento da rede hidrográfica, o modelo divide a bacia hidrográfica em sub-bacias. São geradas diversas sub-bacias dependendo do nível de detalhamento da rede hidrográfica. Porém, estas sub-bacias foram mescladas até se alcançar a conformação desejada, resultando em quatro sub-bacias. Em sequência são inseridos o mapa de uso das terras (o qual teve os usos reclassificados de acordo com as recomendações do SWAT), mapa pedológico (as informações referentes a cada classe de solo presente na BHRP foram adicionadas no banco de dados de solos do modelo SWAT) e definição das classes de declividade, a partir dessas informações são criadas as HRUs (NEITSCH et al., 2011). Após esses procedimentos foram inseridos os dados meteorológicos e modificou-se os fatores $\mathrm{C}, \mathrm{P}$ da equação universal de perda de solo e curva-número $(\mathrm{CN})$ para a condição II de umidade do solo;

- Simulação hidrológica: após a etapa anterior, realizou-se a simulação hidrológica inicial. Essa simulação corresponde ao período de 2004 a 2013 com três anos de aquecimento do modelo. O período de aquecimento é necessário para adequar o modelo às características edafoclimáticas da bacia hidrográfica e minimizar as incertezas inerentes ao processo de modelagem hidrológica (ARNOLD et al., 1998).

- Calibração hidrológica: após a simulação hidrológica foi realizada a calibração do modelo, a qual será melhor detalhada no item "Calibração hidrológica".

- Simulação hidrológica com os parâmetros já calibrados: posteriormente ao procedimento de calibração hidrológica os novos valores dos parâmetros calibrados foram inseridos no modelo SWAT e realizou-se as simulações com os parâmetros já calibrados, desse modo os resultados obtidos são representativos dos processos hidrológicos que ocorrem na BHRP.

\section{CALIBRAÇÃO DA VAZÃO COM DIFERENTES FONTES DE DADOS METEOROLÓGICOS}

Em estudos de modelagem e simulação hidrológica é de fundamental importância realizar a calibração do modelo hidrológico utilizado (MORIASI et al., 2007; ABBASPOUR et al., 2015; BRIGHENTHI et al., 2016; BLAINSKI; ACOSTA; NOGUEIRA, 2017). Calibrar o modelo hidrológico consiste em encontrar o melhor ajuste dos dados simulados aos observados (ABBASPOUR et al., 2015; BLAINSKI; ACOSTA; NOGUEIRA, 2017; ABBASPOUR; VAGHEFI; SRINIVASAN, 2017), diminuindo assim as incertezas inerentes à modelagem. Em razão de haver duas fontes de dados meteorológicos: dados meteorológicos observados e dados meteorológicos de reanálise, foram realizadas duas calibrações hidrológicas (calibração da vazão com os dados meteorológicos observados e, calibração da vazão com os dados meteorológicos de reanálise). A calibração da vazão com os dados meteorológicos observados foi realizada por Martins et al. (2020), assim os novos valores dos parâmetros mais sensíveis obtidos por esses autores foram inseridos no modelo SWAT para a realização da simulação hidrológica. A calibração da vazão com os dados meteorológicos de reanálise foi realizada neste trabalho e será explicada a seguir.

Para a realização deste procedimento utilizou-se o software SWAT: Calibration and Uncertainty Programs (SWAT-CUP), utilizando-se o algoritmo Sequential Uncertainty Fitting (SUFI-2), o qual é amplamente utilizado em processos de calibração hidrológica do modelo SWAT. Durante o procedimento de calibração, pelo programa SWAT-CUP, foram realizadas 750 simulações, onde o programa, por meio da análise de sensibilidade, ajustou uma série de parâmetros que tem maior influência nos dados simulados de vazão. A obtenção dos parâmetros mais sensíveis para ajuste da vazão foi obtida a partir do trabalho realizado por Paz et al. (2018) e Martins et al. (2020). A análise 
de sensibilidade dos parâmetros foi realizada de forma semiautomática, com a utilização do método SUFI-2, o qual foi definido em razão de sua eficácia e ampla utilização em diversas regiões do Brasil (BRIGHENTI; BONUMÁ; CHAFFE, 2016; PONTES et al., 2016; FRANCO e BONUMÁ, 2017).

Para a realização do procedimento de calibração foram elencados os parâmetros que exercem maior influência no ciclo hidrológico e seus intervalos definidos (Tabela 3). Destaca-se que os parâmetros selecionados bem como o intervalo utilizado foram determinados por meio de revisão de literatura (ANDRADE; MELO; BESKOW, 2013; BLAINSKI; ACOSTA; NOGUEIRA, 2017; PAZ et al., 2018; MARTINS et al., 2020).

Tabela 3 - Descrição, método de substituição e intervalo dos parâmetros utilizados para análise de sensibilidade no SWAT-CUP.

\begin{tabular}{|c|c|c|c|c|}
\hline \multirow{2}{*}{ Parâmetro } & \multirow{2}{*}{ Descrição } & \multirow{2}{*}{ Método } & \multicolumn{2}{|c|}{ Intervalo } \\
\hline & & & Mín & Máx \\
\hline CN2 & $\begin{array}{l}\text { Curva-Número para a condição II de umidade } \\
\text { (adimensional) }\end{array}$ & r_relative & $-0,2$ & 0,2 \\
\hline ALPHA & Fator de recessão do fluxo de base (dias) & v_replace & 0 & 1 \\
\hline GW_DELAY & Tempo de retardo do fluxo subterrâneo (dias) & v_replace & 30 & 450 \\
\hline GW_QMN & $\begin{array}{l}\text { Profundidade mínima do aquífero superficial } \\
\text { para escoamento superficial (mm H2O) }\end{array}$ & v_replace & 0 & 2 \\
\hline ESCO & $\begin{array}{l}\text { Fator de compensação da evaporação de } \\
\text { água do solo (adimensional) }\end{array}$ & v_replace & 0 & 1 \\
\hline SOW_AWC & $\begin{array}{c}\text { Capacidade de água disponível (mm } \\
\mathrm{H} 2 \mathrm{O} / \mathrm{mm} \text { solo) }\end{array}$ & r_relative & $-0,25$ & 0,25 \\
\hline SOL_Z & Profundidade da camada de solo (mm) & r_relative & $-0,25$ & 0,25 \\
\hline $\mathrm{CH} \_\overline{\mathrm{K}} 2$ & $\begin{array}{l}\text { Condutividade hidráulica efetiva no canal } \\
\text { principal }(\mathrm{mm} / \mathrm{h})\end{array}$ & v_replace & $-0,1$ & 0,1 \\
\hline GW_REVAP & $\begin{array}{l}\text { Coeficiente de escoamento subterrâneo } \\
\text { (adimensional) }\end{array}$ & v_replace & 0,02 & 0,2 \\
\hline RCHRG_DP & $\begin{array}{c}\text { Fração de percolação para o aquífero } \\
\text { profundo (adimensional) }\end{array}$ & v_replace & 0 & 1 \\
\hline SLSUBBSN & Comprimento médio do declive (m) & r_relative & $-0,25$ & 0,25 \\
\hline SOL_K & Condutividade hidráulica do solo $(\mathrm{mm} / \mathrm{h})$ & r_relative & $-0,25$ & 0,25 \\
\hline USLE_P & Fator P da USLE & r_relative & $-0,25$ & 0,25 \\
\hline SOL_ALB & Albedo do solo (adimensional) & r_relative & $-0,25$ & 0,25 \\
\hline $\mathrm{CH} \_\mathrm{N} 2$ & $\begin{array}{c}\text { Coeficiente de Manning para o canal principal } \\
\text { (adimensional) }\end{array}$ & v_replace & $-0,01$ & 0,3 \\
\hline BIOMIX & $\begin{array}{l}\text { Eficiência do revolvimento biológico } \\
\text { (adimensional) }\end{array}$ & v_replace & 0 & 1 \\
\hline EPCO & $\begin{array}{l}\text { Fator de compensação da evaporação de } \\
\text { água pelas plantas (adimensional) }\end{array}$ & v_replace & 0 & 1 \\
\hline SURLAG & $\begin{array}{l}\text { Coeficiente de retardamento do escoamento } \\
\text { superficial (adimensional) }\end{array}$ & v_replace & 0 & 24 \\
\hline REVAPMN & $\begin{array}{l}\text { Mínimo de água para a ocorrência do } \\
\text { escoamento superficial (adimensional) }\end{array}$ & v_replace & 0 & 1000 \\
\hline
\end{tabular}

"Método r_relative: o valor atual do parâmetro é multiplicado por $(1+x)$, onde $x$ é o valor obtido na melhor simulação da iteração; Método v replace: o valor atual do parâmetro é substituído por outro valor, obtido na melhor simulação da iteração. Fonte - ABBASPOUR, 2015; PAZ et al., (2018), MARTINS et al., (2020), adaptado.

Para a análise de sensibilidade global avaliou-se os índices $t$-stat e $p$-value conjuntamente, de modo que, o parâmetro foi considerado mais sensível quando, apresentou o maior valor absoluto de $t$-stat e sua maior significância ( $p$-value mais próximo de zero). Como função objetivo utilizou-se o coeficiente 
de eficiência estatística de Nash e Sutcliffe (equação 2), o índice PBIAS (equação 3) e o RSR (equação 4), de acordo com Moriasi et al. (2007).

$$
\begin{aligned}
& N S=1-\frac{\sum_{i=0}^{n}\left(Y_{i}^{o b s}-Y_{i}^{s i m}\right)^{s}}{\sum_{i=0}^{n}\left(Y_{i}^{o b s}-\overline{Y_{i}^{o b s}}\right)^{s}} \\
& \text { PBIAS }=\left[\frac{\sum_{i=1}^{n}\left(Y_{i}^{0 b s}-Y_{i}^{s i m}\right) \times(100)}{\sum_{i=1}^{n}\left(Y_{i}^{0 b s}\right)}\right] \\
& R S R=\frac{R M S E}{S T D E V_{0 b s}}=\frac{\left[\sqrt{\left.\sum_{i=1}^{n}\left(Y_{i}^{o b s}-Y_{i}^{s i m}\right)^{2}\right]}\right.}{\left[\sum_{i=1}^{n}\left(Y_{i}^{o b s}-Y^{m e a n}\right)^{2}\right]}
\end{aligned}
$$

em que: $Y_{i}^{o b s}=$ dado observado; $Y_{i}^{\text {sim }}=$ dado simulado; $Y^{\text {mean }}=$ média dos dados observados; $\overline{Y_{a}^{\text {obs }}}=$ média dos dados observados no dia i; RMSE: é o erro quadrático médio; STDEV padrão dos dados observados; NS = coeficiente de Nash e Sutcliffe, adimensional; RSR = taxa de desvio padrão das observações, adimensional; PBIAS = viés dos dados simulados em relação aos observados, porcentagem.

\section{RESULTADOS E DISCUSSÃO}

\section{ANÁLISE ESTATÍSTICA ENTRE OS DADOS METEOROLÓGICOS OBSERVADOS E DE REANÁLISE}

Anteriormente à realização da simulação hidrológica realizou-se a análise estatística dos dados meteorológicos observados e de reanálise. Nessa análise, comparou-se separadamente os dados meteorológicos das estações meteorológicas de Cordeirópolis e Nova Odessa, com os dados de reanalise do CFRS. Nas tabelas 4 e 5 são apresentados os indicadores estatísticos, entre os postos meteorológicos de Cordeirópolis/Nova Odessa (dados observados) vs. dados de reanálise, respectivamente.

Tabela 4 - Análise estatística dos dados meteorológicos observados da estação de Cordeirópolis em comparação com os dados meteorológicos de reanálise.

\begin{tabular}{cccccccc}
\hline Dados & d mod & MAE & RMSE & NS & Rpearson & $\mathbf{R}^{2}$ & PBIAS \\
\hline Precipitação pluviométrica $(\mathrm{mm})$ & 0,53 & 4,85 & 12,33 & -1078 & 0,34 & 0,11 & 3,05 \\
${ }^{*} T$ Tmp máxima $\left({ }^{\circ} \mathrm{C}\right)$ & 0,66 & 2,15 & 3,20 & 0,24 & 0,701 & 0,49 & $-0,73$ \\
${ }^{*} T m p$ mínima $\left({ }^{\circ} \mathrm{C}\right)$ & 0,70 & 1,88 & 2,23 & 0,69 & 0,87 & 0,76 & 1,05 \\
\hline
\end{tabular}

*Tmp: temperatura; dmod: índice de Willmott modificado; MAE: erro médio absoluto; RMSE: erro quadrático médio; NS: índice de Nash e Sutcliffe; Rpearson: coeficiente de correlação de Pearson; R²: coeficiente de determinação; PBIAS: percentual de viés dos dados simulados em relação aos dados observados.

Tabela 5 - Análise estatística para avaliação dos dados meteorológicos da estação de Nova Odessa em comparação com os dados meteorológicos de reanálise.

\begin{tabular}{cccccccc}
\hline Dados & d mod & MAE & RMSE & NS & Rpearson & R $^{2}$ & PBIAS \\
\hline Precipitação pluviométrica $(\mathrm{mm})$ & 0,54 & 4,95 & 10,91 & $-0,55$ & 0,35 & 0,12 & 1,44 \\
${ }^{*} T$ mp máxima $\left({ }^{\circ} \mathrm{C}\right)$ & 0,60 & 2,76 & 3,43 & 0,28 & 0,75 & 0,56 & $-1,79$ \\
${ }^{*} T m p$ mínima $\left({ }^{\circ} \mathrm{C}\right)$ & 0,74 & 1,75 & 2,34 & 0,70 & 0,88 & 0,78 & 1,15 \\
\hline
\end{tabular}

"Tmp: temperatura; dmod: índice de Willmott modificado; MAE: erro médio absoluto; RMSE: erro quadrático médio; NS: índice de Nash e Sutcliffe; Rpearson: coeficiente de correlação de Pearson; R²: coeficiente de determinação; PBIAS: percentual de viés dos dados simulados em relação aos dados observados. 
Por meio da análise das tabelas 4 e 5 , pode-se observar que existem diferenças significativas entre os dados de precipitação pluviométrica observados da estação de Cordeirópolis e Nova Odessa e os dados meteorológicos de reanálise. Estas diferenças são elucidadas pelos $\mathrm{R}^{2}$ que indicou fraca correlação entre os dados observados e de reanálise (CONTI, 2009), índice NS que indicou péssimo ajuste dos dados de reanálise em relação aos observados, dmod também indicou baixa correlação entre esses dados. No entanto, o valor de PBIAS indica que os dados meteorológicos de reanálise estão subestimados em relação aos dados observados, porém de acordo com Moriasi et al. (2007), o valor de PBIAS obtido é classificado como muito bom. A análise preliminar dos dados de precipitação pluviométrica de reanálise indica que estes estão subestimados em relação aos dados observados e apresentam baixa correlação com estes. Destaca-se que, estas diferenças entre as duas fontes de dados podem ser atribuídas em razão da alta variabilidade espacial da precipitação pluviométrica (BARATTO; WOLLMAN; HOPE, 2015).

As análises estatísticas da temperatura mínima do ar permitem inferir que há forte correlação entre os dados de reanálise e os dados observados ( $\mathrm{d}$ mod, Rpearson, $\mathrm{R}^{2}$ ), bom ajuste dos dados de reanálise aos dados observados (NS>0,65), de acordo com Moriasi et al. (2007) e subestimação dos dados de reanálise em relação aos observados. No entanto de acordo com a classificação de Moriasi et al. (2007), este valor é considerado como muito bom. Em relação à comparação realizada com os dados de temperatura máxima observou-se correlação fraca e moderada $\left(R^{2}\right)$, o coeficiente de Pearson indicou alto nível de correlação.

A análise estatística realizada entre os dados observados e de reanálise mostrou que não existe boa correlação entre os dados de precipitação observados nos postos meteorológicos de Cordeirópolis e Nova Odessa com os dados de reanálises do CFRS, ao contrário do que foi observado para os dados de temperatura. No caso da precipitação, sabe-se que esse parâmetro tem elevada variabilidade espacial o que pode ter influenciado significativamente os resultados das análises estatísticas.

As figuras 3 , 4 e 5 apresentam as médias mensais de precipitação pluviométrica, temperatura máxima e temperatura mínima, respectivamente, dos dados observados e de reanálise. $\mathrm{Na}$ análise dessas figuras se observa que os dados de precipitação pluviométrica de reanálise são superestimados em relação aos dados observados, diferindo do que foi observado nas análises estatísticas. Essa diferença pode estar relacionada ao fato de que para a realização das análises estatísticas as estações meterorológicas dos dados observados foram comparadas separadamente, entretanto as figuras foram elaboradas a partir dos dados médios das estações meteorológicas. Em realação aos dados de temperatura máxima e mínima, não foram observadas diferenças entre as análises estatísticas e as análises gráficas.

Figura 3 - Blox Plot das médias mensais de precipitação pluviométrica dos dados observados 20042013 (a) e dados de reanálise (b).

a)

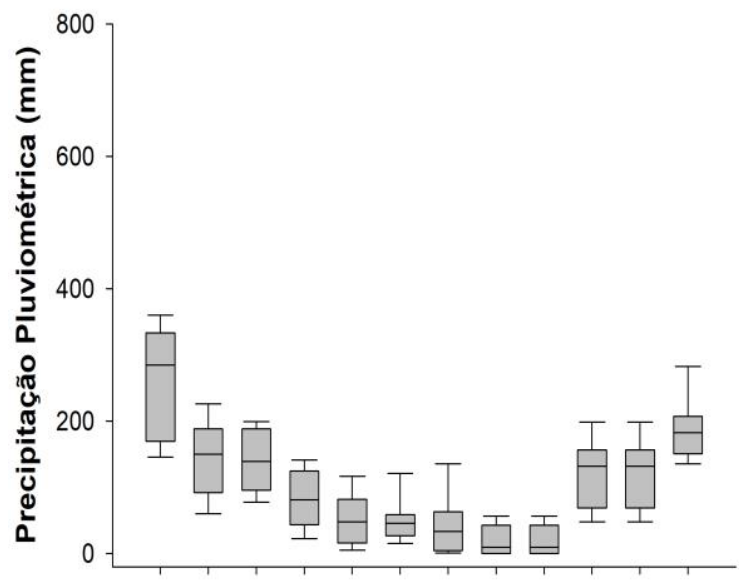

Jan Fev Mar Abr Mai Jun Jul Ago Set Out Nov Dez

Meses

b)

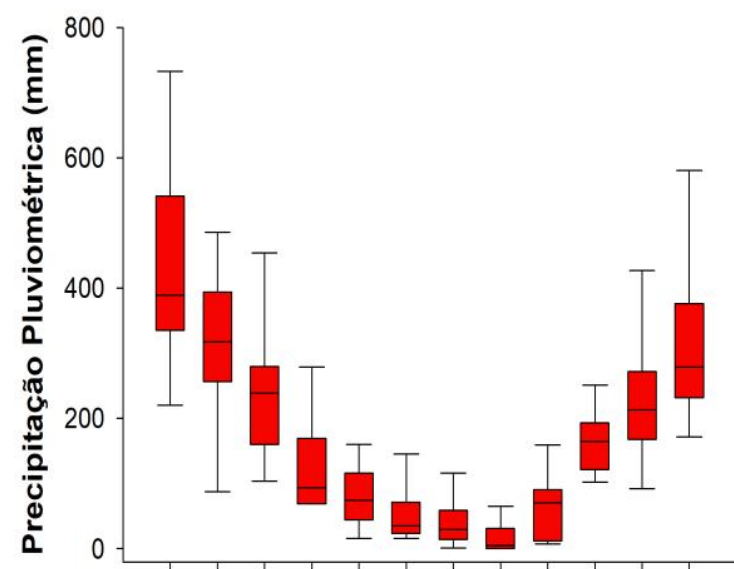

Jan Fev Mar Abr Mai Jun Jul Ago Set Out Nov Dez

Meses 
Figura 4 - Blox Plot das médias mensais de temperatura máxima dos dados observados 2004-2013 (a) e dados de reanálise (b).

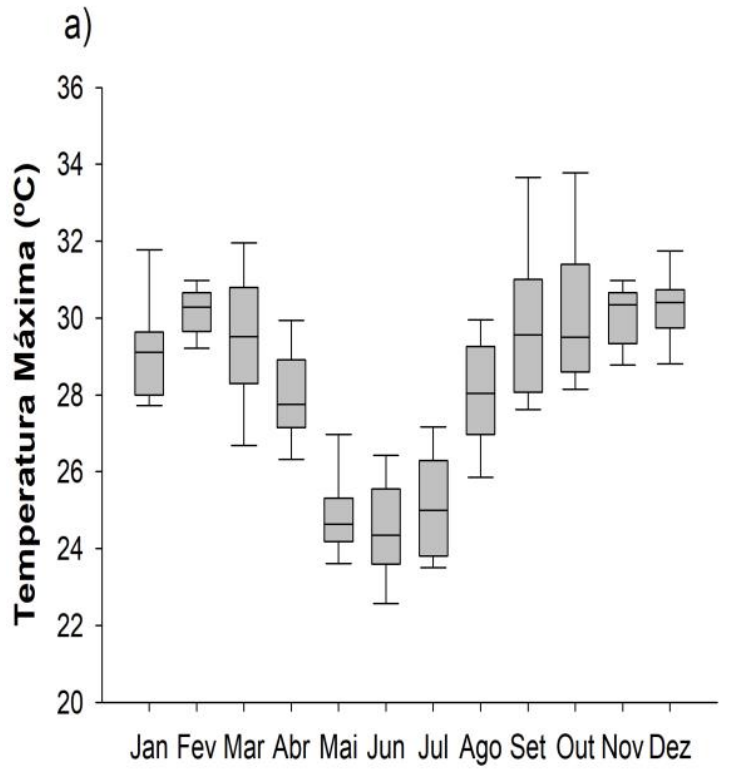

Meses

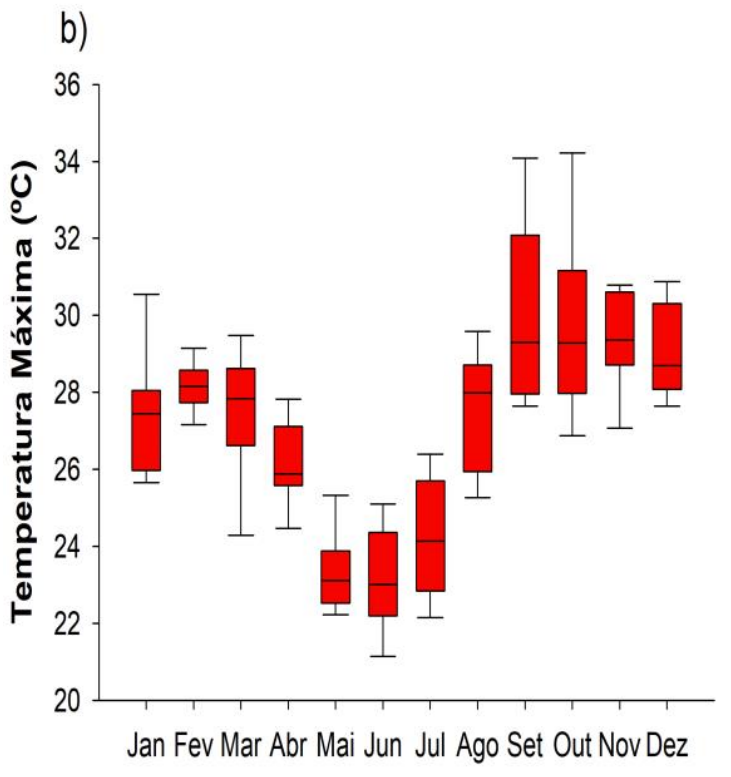

Meses

Figura 5 - Blox Plot das médias mensais de temperatura mínima dos dados observados 2004-2013 (a) e dados de reanálise (b).

a)

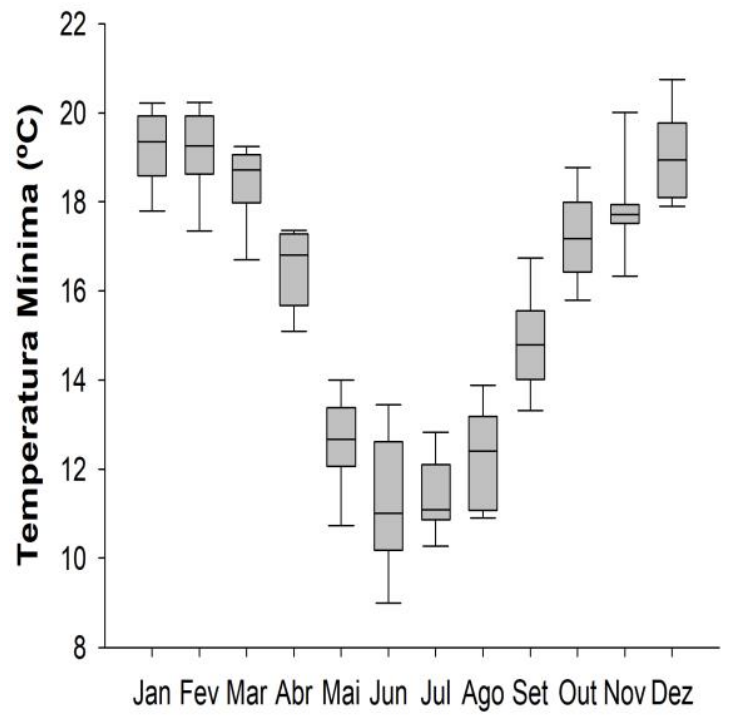

Meses b)

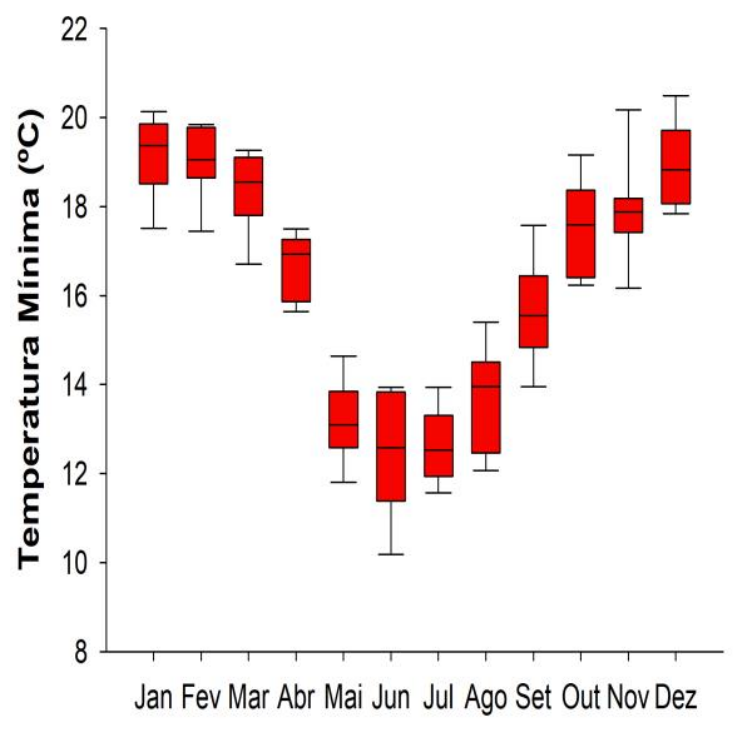

Meses

\section{ANÁLISE DE SENSIBILIDADE E CALIBRAÇÃO HIDROLÓGICA}

$\mathrm{Na}$ etapa de calibração hidrológica realizou-se a análise de sensibilidade a fim de se identificar os parâmetros mais sensíveis, ou seja, os parâmetros que quando têm seus valores alterados resultam em modificações significativas na vazão (ABBASPOUR, 2015). Os parâmetros mais sensíveis na análise de sensibilidade com os dados meteorológicos de reanálise e com os dados meteorológicos observados, bem como os novos valores desses parâmetros, são apresentados na tabela 6 . 
Tabela 6 - Parâmetros mais sensíveis e valores atualizados na simulação com os dados meteorológicos de reanálise e com os dados meteorológicos observados.

\begin{tabular}{|c|c|c|c|c|}
\hline Parâmetro & Descrição & $\begin{array}{l}\text { Método de } \\
\text { substituição }\end{array}$ & $\begin{array}{c}\text { Valores } \\
\text { atualizados } \\
\text { (reanálise) }^{*}\end{array}$ & $\begin{array}{c}\text { Valores } \\
\text { atualizados } \\
\text { (observados) }^{\star \star}\end{array}$ \\
\hline CN2 & $\begin{array}{l}\text { Curva-número na condição II de } \\
\text { umidade (adimensional) }\end{array}$ & r_relative & 0,000478 & 0,2081 \\
\hline GW_DELAY & $\begin{array}{l}\text { Tempo de retardo do fluxo subterrâneo } \\
\text { (dias) }\end{array}$ & v_replace & 80,88 & 20,359 \\
\hline ESCO & $\begin{array}{l}\text { Fator de compensação da evaporação } \\
\text { de água no solo (adimensional) }\end{array}$ & v_replace & 0,015 & 0,9781 \\
\hline SOL_AWC & $\begin{array}{l}\text { Capacidade de água disponível (mm } \\
\qquad \mathrm{H} 20 / \mathrm{mm} \text { de solo) }\end{array}$ & r_relative & 0,86 & 0,316 \\
\hline RCHRG_DP & $\begin{array}{l}\text { Fração de percolação para o aquífero } \\
\text { profundo (adimensional) }\end{array}$ & v_replace & 0,36 & 0,03 \\
\hline $\mathrm{CH} \_\mathrm{N} 2$ & $\begin{array}{l}\text { Coeficiente de Manning do canal } \\
\text { principal (adimensional) }\end{array}$ & v_replace & 0,3 & 0,084 \\
\hline EPCO & $\begin{array}{l}\text { Fator de compensação da evaporação } \\
\text { de água pelas plantas (adimensional) }\end{array}$ & v_replace & 0,98 & 0,44 \\
\hline RCHRG_DP & $\begin{array}{c}\text { Fração de percolação para o aquífero } \\
\text { profundo (adimensional) }\end{array}$ & v_replace & ---- & 0,03 \\
\hline SLSUBSN & Comprimento médio do declive $(\mathrm{m})$ & r_relative & ---- & 0,179 \\
\hline
\end{tabular}

Percebe-se que, em geral, os parâmetros mais sensíveis foram os mesmos. Os parâmetros SLSUBSN e SOL_K foram sensíveis na calibração em que se utilizou os dados meteorológicos observados e não apresentaram o mesmo grau de sensibilidade na calibração que utilizou os dados meteorológicos de reanálise. Esse fato pode estar relacionado com as diferentes fontes de dados meteorológicos utilizadas no processo de calibração, principalmente no que se refere à precipitação (NEITSCH et al., 2011). A precipitação é um dos principais componentes que interferem na dinâmica do ciclo hidrológico, o que pode explicar as diferenças na análise de sensibilidade com as duas fontes de dados meteorológicos.

Quando comparados os índices estatísticos da calibração realizada com os dados meteorológicos observados e de reanálise, percebe-se que o ajuste dos dados simulados aos observados tem a mesma classificação (satisfatório). No entanto, o ajuste dos dados foi melhor na simulação em que se utilizou os dados meteorológicos observados (Tabela 7). Em contrapartida, a classificação do PBIAS foi melhor classificada na simulação com os dados meteorológicos de reanálise, havendo uma superestimação dos dados simulados em relação aos observados em 7\%.

Tabela 7 - Índices estatísticos dos dados observados vs. dados de reanálise no procedimento de calibração.

\begin{tabular}{ccccc}
\hline Índices & Observados $^{*}$ & Classificação $^{* *}$ & Reanálise & Classificação $^{\text {NS }}$ \\
NBIAS & 0,64 & Satisfatório & 0,51 & Satisfatório \\
RSR & 15,2 & Satisfatório & $-7,00$ & Muito Bom \\
\hline
\end{tabular}

"Resultados obtidos no trabalho de Martins et al., 2020; ${ }^{* *}$ Classificação conforme Moriasi et al., 2007.

Conforme observado na figura 6 a vazão simulada a partir dos dados meteorológicos de reanálise foi superestimada à vazão simulada com os dados meteorológicos observados, no entanto de acordo com o observado na tabela 7 , esta diferença não comprometeu o processo de calibração hidrológica do modelo. 
Figura 6 - Vazão simulada com os dados meteorológicos observados vs. dados meteorológicos de reanálise.

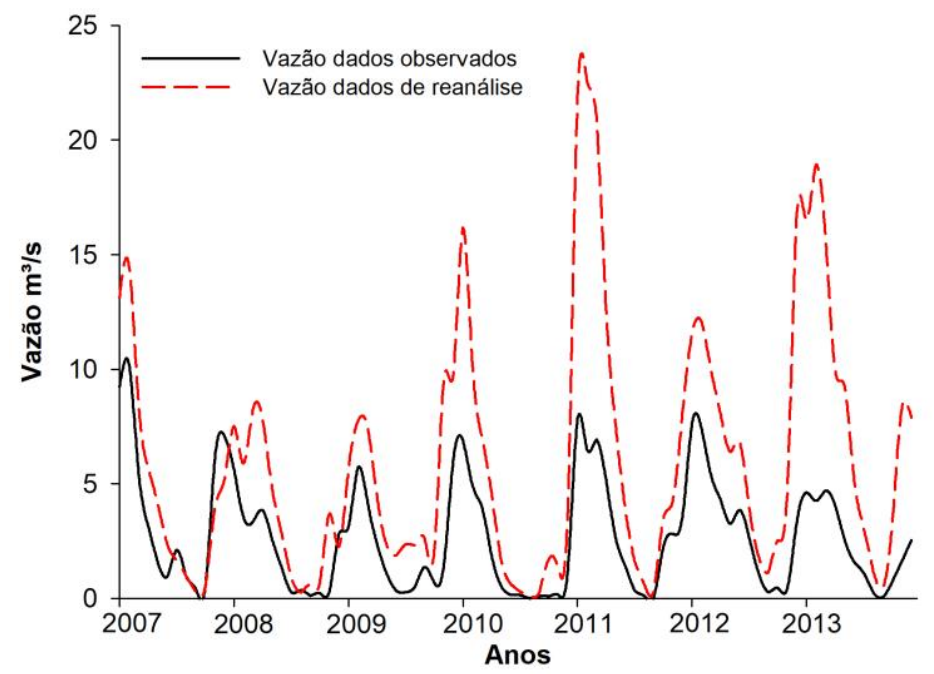

Ao comparar a vazão simulada com os dados meteorológicos observados e a vazão simulada com os dados meteorológicos de reanálise foi possível verificar diferenças entre os valores, mas principalmente nos valores de pico. No entanto, a análise comparativa entre os dados simulados de reanálise e observados indica forte correlação entre ambos. Embora as fontes de dados são diferentes, estas não prejudicaram o processo de calibração, sendo, portanto, possível realizar a calibração hidrológica do modelo SWAT com os dados meteorológicos de reanálise. Embora a figura 6 evidencie as diferenças entre as vazões simuladas com as diferentes fontes de dados meteorológicos a análise de regressão demonstra um bom ajuste entre as vazões simuladas com as duas fontes de dados (Figura 7).

Figura 7 - Análise de regressão dos dados de vazão simulados a partir dos dados meteorológicos de reanálise (Vazão CFSR) e vazão simulada a partir dos dados meteorológicos observados (Vazão CIIAGRO).

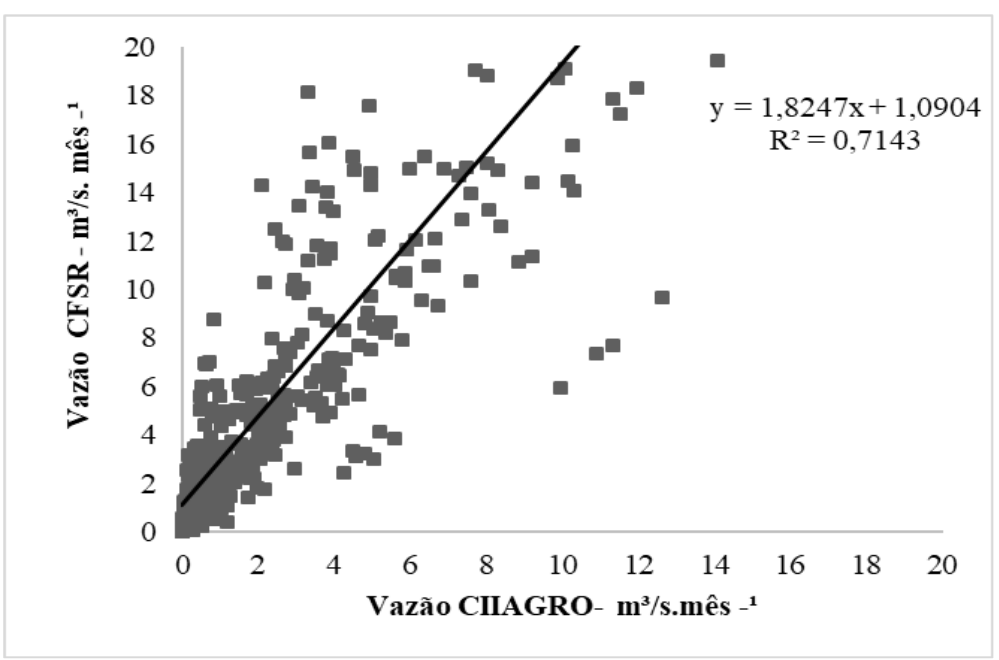

Trabalhos como o de Paz et al. (2018), Monteiro et al. (2015) realizaram a calibração hidrológica do modelo SWAT com dados meteorológicos de reanálise obtendo índices estatísticos satisfatórios. Os resultados obtidos nesses trabalhos corroboram com o presente trabalho no que se refere à possibilidade de utilização de dados de reanálise como alternativa ao preenchimento de falhas e/ou ausências de dados meteorológicos observados, para a realização do monitoramento e planejamento agroambiental de bacias hidrográficas brasileiras. 
Paz et al. (2018), utilizaram dados meteorológicos de reanálise do CFSR e dados meteorológicos observados para a realização da modelagem hidrológica com o SWAT. Concluíram que os melhores índices estatísticos do processo de calibração foram obtidos com a utilização de dados meteorológicos locais. No entanto, quando se utilizou dados meteorológicos locais associados aos dados de reanálise (para o preenchimento de falhas), houve uma melhora no processo de calibração hidrológica. Esses resultados indicam as possibilidades de utilização de dados de reanálise para o aprimoramento do processo de modelagem hidrológica.

Monteiro et al. (2015) utilizaram diferentes fontes de dados meteorológicos de reanálise e compararam com dados observados, a fim de determinar quais das fontes melhor representariam a precipitação no território brasileiro e seriam mais adequados para a realização de modelagem hidrológica. As fontes de dados meteorológicos de reanálise utilizadas por esses autores foram: CFSR e a metodologia WATCH Forcing Data aplicada aos dados ERA- Interim (WFDEI). Após a realização de análises estatísticas e a calibração e validação hidrológica do modelo SWAT os autores concluíram que os dados WFDEI são mais indicados para a realização de modelagem hidrológica em comparação com os dados do CFSR.

Neste estudo utilizou-se apenas uma fonte de dados de reanálise, a qual já foi suficiente para a realização da calibração hidrológica do modelo SWAT e, para as variáveis temperaturas máximas e mínimas, apresentou boa correlação com os dados observados. A utilização de outras fontes de dados, como a utilizada por Monteiro et al. (2015), pode ser uma alternativa para melhorar a qualidade dos dados pluviométricos que poderão refletir em uma melhoria no processo de modelagem hidrológica, principalmente na representação da vazão de pico, que neste estudo foi superestimada ao utilizar os dados provenientes do CFSR.

\section{CONSIDERAÇÕES FINAIS}

A utilização de dados meteorológicos de reanálise, obtidos na plataforma CFSR, são adequados para a realização da simulação hidrológica com o modelo SWAT, o que é evidenciado por meio dos índices estatísticos satisfatórios obtidos no procedimento de calibração hidrológica, neste trabalho. Desse modo, essa fonte de dados pode ser utilizada como alternativa à ausência de dados e/ou preenchimento de falhas para a realização de modelagem hidrológica.

Os dados meteorológicos da plataforma CFSR são uma alternativa para o preenchimento e/ou ausência de dados meteorológicos observados. Esses dados podem ser usados para a realização da simulação de cenários atuais e alternativos do uso e ocupação do solo e, principalmente, para a realização do planejamento agroambiental na bacia hidrográfica do Ribeirão do Pinhal.

Os índices estatísticos obtidos no processo de calibração indicam a aplicabilidade do modelo SWAT para a realização de simulação hidrológica com fontes de dados meteorológicos de reanálise.

\section{AGRADECIMENTOS}

Os autores agradecem à Coordenação de Aperfeiçoamento de Pessoal de Nível Superior (CAPES) pela concessão da bolsa de mestrado ao primeiro autor.

\section{REFERÊNCIAS}

ABBASPOUR, K. C. SWAT-CUP: SWAT Calibration and Uncertainty Programs - A user manual. Ewag,100p. 2015. Disponível em: <https://swat.tamu.edu/media/114860/usermanual_swatcup.pdf>. Acesso em: 02 fev. 2019.

ABBASPOUR, K. C., VAGHEFI, S. A., SRINIVASAN, R. A guideline for successful calibration and uncertainty analysis for soil and water assessment: A review of papers from the 2016 international SWAT conference. Water [Online], v.10 (1),n.6, dez. 2017. Disponível em: < https://www.mdpi.com/2073-4441/10/1/6/htm>. Acesso em: 22 abr. 2019. https://doi.org/10.3390/w10010006

ABBASPOUR, K. C., ROUHOLAHNEJAD, E., VAGHEFI, S., SRINIVASAN, R., YANG, H., Kløve, B. A 
continental-scale hydrology and water quality model for Europe: Calibration and uncertainty of a highresolution large-scale SWAT model. Journal of Hydrology. v. 524, mai. 2015. Disponível em:< https://www.sciencedirect.com/science/article/pii/S0022169415001985>.Acesso em: 20 abr. 2019. https://doi.org/10.1016/i.jhydrol.2015.03.027

ALVARES, C.A., STAPE, J. L., SENTELHAS, P. C., GONÇALVES, J. L. M., SPAROVEK, G. Köppen's climate classification map for Brazil. Meteorologische Zeitschrift [Online], v. 22, n.6, dec. 2013.

https://www.schweizerbart.de/papers/metz/detail/22/82078/Koppen_s_climate_classification_map_for _Brazil>. Acesso em: 10 nov. 2018. https://doi.org/10.1127/0941-2948/2013/0507

ANDRADE, M. A., MELLO, C.R., BESKOW, S. Simulação hidrológica em uma bacia hidrográfica representativa dos Latossolos na região Alto Rio Grande, MG. Revista Brasileira de Engenharia Agrícola e Ambiental, Campina Grande, v.17, n.1, 2013. Disponível em:< https://www.scielo.br/scielo.php?pid=S1415-43662013000100010\&script=sci_abstract\&tlng=pt>.

Acesso em: 22 mai. 2019. https://doi.org/10.1590/S1415-43662013000100010

ARNOLD, J. G., MORIASI, D. N., GASSMAN, P. W., ABBASPOUR, K. C., WHITE, M. J., SRINIVASAN, R., SANTHI, C., HARMEL, R. D., van GRIENSVEN, A., VAN LIEW, M. W., KANNAN, N., JHA, M. K. SWAT: Model use, calibration and validation. American Society of Agricultural and

Biological Engineers $\quad$ v $55, \mathrm{n} 4,2012$ https://swat.tamu.edu/media/90102/azdezasp.pdf>. Acesso em: 05 jun.2019. https://doi.org/10.13031/2013.42256

ARNOLD, J.G., SRINIVASAN, R., MUTTIAH, R. S., WILLIANS, J. R. Large area hydrologic modeling and assessment part I: model development. Journal of the American Water Resources Association, v.34, n.1, 1998. Disponível em:< https://onlinelibrary.wiley.com/doi/10.1111/j.17521688.1998.tb05961.x>. Acesso em: 03 mai. 2019. https://doi.org/10.1111/j.1752-1688.1998.tb05961.x

BARATTO, J., WOLLMANN, C. A., HOPPE, I. L. Distribuição da precipitação pluviométrica no período veranil e invernal de 2013/2014 na área urbana de Santa Maria/RS e seu entorno. Ciência e Natura, v. 37, n.3, 2015. Disponível em:< https://periodicos.ufsm.br/revistas/ojs2.2.2/index.php/cienciaenatura/article/view/18026?source=/revistas/ojs-

2.2.2/index.php/cienciaenatura/article/view/18026>. Acesso em: 10 nov. 2018. https://doi.org/10.5902/2179460X18026

BLAINSKI, E., ACOSTA, E., NOGUEIRA, P. C. P. Calibração e validação do modelo SWAT para simulação hidrológica em uma bacia hidrográfica do litoral norte catarinense. Ambiente e Água - An Interdisciplinary Journal of Applied Science [Online], v.12, n.2, 2017.Disponível em:< https://www.scielo.br/pdf/ambiagua/v12n2/1980-993X-ambiagua-12-02-00226.pdf>. Acesso em: 25 mar. 2019.https://doi.org/10.4136/ambi-agua.1951

BRESSIANI, D. A., GASSMAN, P. W., FERNANDES, J. G., GARBOSSA, L. H. P., SRINIVASAN, R., BONUMÁ, N. B., MEDIONDO, E. M. Review of Soil and Water Assessment Tool (SWAT) applications in Brazil: Challenges and prospects. International Journal of Agricultural and Biological

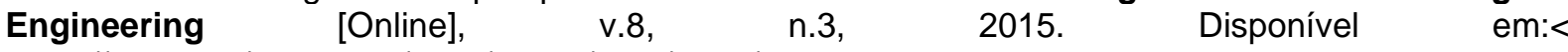
https://ijabe.org/index.php/ijabe/article/view/1765/0>. Acesso em: 15 jan. 2019.

BRIGHENTI, T. M., BONUMÁ, N. B., CHAFFE, P. L. B. Calibração hierárquica do modelo swat em uma bacia hidrográfica catarinense. Revista Brasileira de Recursos Hidricos [Online], v.21, n.1, 2016.Disponível em:< https://www.scielo.br/pdf/rbrh/v21n1/2318-0331-rbrh-21-1-53.pdf>. Acesso em: 30 mar. 2019. https://doi.org/10.21168/rbrh.v21n1.p53-64

CONTI, F. Biometria, regressão e correlação. Laboratório de Informática, ICB-UFPA. Paraíba, 2009.

CPRM - Serviço Geológico do Brasil. (2006). Mapa de geodiversidade do Brasil, escala 1:2.500.000. Legenda expandida. Brasília: CPRM, 2006, 68p.

FRANCO, A.C.L. e BONUMÁ, N.B. Multi-variable SWAT model calibration with remotely sensed evapotranspiration and observed flow. Revista Brasileira de Recursos Hídricos, v.22, n.35, 2017.Disponível em:< https://www.scielo.br/pdf/rbrh/v22/2318-0331-rbrh-22-e35.pdf>. Acesso em: 04 abr. 2019. https://doi.org/10.1590/2318-0331.011716090

$\begin{array}{lllll}\text { Caminhos de Geografia } \quad \text { Uberlândia-MG } & \text { v. 22, n. } 80 \quad \text { abr./2021 } & \text { p. 234-252 } & \text { Página } 250\end{array}$


GASSMAN, P. W., REYES, M. R., GREEN, C. H., ARNOLD, J. G. The Soil and Water Assessment Tool: Historical Development, Applications, and Future Research Directions. American Society of Agricultural and Biological Engineers. v. 50, n.4, 2007. Disponível em:< https://www.card.iastate.edu/research/resource-and-environmental/items/asabe_swat.pdf>. Acesso em: 15 nov.2018. https://doi.org/10.13031/2013.23637

GLOBAL WEATHER. Global Weather Data for SWAT. 2019. Disponível em:< https://globalweather.tamu.edu/>. Acesso em: 25 fev. 2019.

IBGE. (2012). Manual Técnico da Vegetação Brasileira. 2 ed. rev. ampliada. Rio de Janeiro: IBGE, $271 \mathrm{p}$.

LEGATES, D.R. e MCCABE JR. G.J. Evaluating the use of "goodness-of-fit" measures in hydrologic and hydroclimatic model validation. Water Resources. Research. v.35 n.1, 1999. Disponível em:< https://ui.adsabs.harvard.edu/abs/1999WRR...35..233L/abstract>. Acesso em: 15 jan. 2019. https://doi.org/10.1029/1998WR900018

LEPSCH, I. F., ESPINDOLA, C. R., VISCHI FILHO, O. J., HERNANI, L. C., SIQUEIRA, D. S. Manual para levantamento utilitário do meio físico e classificação de terras no sistema de capacidade de uso. 4a aproximação, Campinas: SBCS, 1983.

LIMEIRA, Prefeitura. Relatório de Gestão e Situação dos Recursos Hídricos - 2017. Disponível em: <https://www.limeira.sp.gov.br/sitenovo/downloads/77a3e7ceb38e7698cd483a5ba1bd77f2.pdf> acesso em: 20 de jun. 2019.

MARTINS, L. L., MARTINS, W. A., MORAES, J. F. L., PEDRO JÚNIOR, M. J., DE MARIA, I. C. Calibração hidrológica do modelo SWAT em bacia hidrográfica caracterizada peça expansão do cultivo da cana-de-açúcar. Revista Brasileira de Geografia Física [Online], v.13, n.02, 2020. Disponível em: <https://periodicos.ufpe.br/revistas/rbgfe/article/view/243477>. Acesso em: $15 \mathrm{abr}$. 2020. https://doi.org/10.26848/rbgf.v13.2.p576-594

MICALISCHEN, M. L. M. M. Uso de dados meteorológicos observacionais e de reanálise para a estimativa da velocidade do vento nos níveis de aerogeradores. Dissertação (Mestrado em Métodos Numéricos em Engenharia). Universidede Federal do Paraná: Curitiba, 2018.

MONTEIRO, J. A. F., STRAUCH, M., SRINIVASAN, R., ABBASPOUR, K., GÜCKER, B. Accuracy of grid precipitation data for Brazil: application in river discharge modelling of the Tocantins catchment. Hydrological Process, v.30, n.9, 2015. Disponível em:< https://onlinelibrary.wiley.com/doi/abs/10.1002/hyp.10708>. Acesso em: 30 set. 2019. https://doi.org/10.1002/hyp.10708

MORAES, J. F, L., ADAMI, S., COELHO, R. M., CHIBA, M. K., AMBRÓSIO, L. A. Diagnóstico Agroambiental para a Bacia Ribeirão do Pinhal. Instituto Agronômico de Campinas. Campinas, 2009.Relatório Técnico.

MORIASI, D. N., ARNOLD, J. G., VAN LIEW, M. W., BINGNER, R. L., HARMEL, R. D., VEITH, T. L. Model Evaluation Guidelines for Systematic Quantification of Accuracy in Watershed Simulations. American Society of Agricultural and Biological Engineers [Online], v.50, n.03,2007. Disponível em:< https://swat.tamu.edu/media/90109/moriasimodeleval.pdf>. Acesso em: 18 mai. 2019.

MUKAKA M. M. Statistics corner: A guide to appropriate use of correlation coefficient in medical research. Malawi Medical Journal, v.24, n.3, 2012. Disponível em:< https://www.ncbi.nlm.nih.gov/pmc/articles/PMC3576830/>. Acesso em: 15 abr. 2019.

NEITSCH, S. L., ARNOLD, J. G., KINIRY, J. R., WILLIANS, J. R. Soil and Water Assessment Tool: Theoretical Documentation. Version 2009. Agricultural Research Service, Texas AgriLife Research, 2011. Disponível em:<https://swat.tamu.edu/media/99192/swat2009-theory.pdf>. Acesso em: 30 out. 2018.

PAZ, Y. M., GALVÍNCIO, J. D., HOLANDA, R. M., SRINIVASA, R., JONES, C. A. Análise de sensibilidade e calibração espacial do modelo SWAT aplicado em uma bacia do litoral pernambucano através de dados climáticos observados e de reanálise. Revista Brasileira de Geografia Física [Online], v.11, n. 2018. Disponível em:< https://periodicos.ufpe.br/revistas/rbgfe/article/view/236313>. Acesso em: 10 jan. 2020. 
PEREIRA, D. R., MARTINEZ, M. A., PRUSKI, F. F., SILVA, D. D. Hydrological simulation in a basin of typical tropical climate and soil using the SWAT model. Part I: Calibration and validation tests. Journal of Hydrology: Regional Studies [Online], v.7, 2016. Disponível em:< https://doi.org/10.1016/j.ejrh.2016.05.002>. Acesso em: 25 jun. 2019. https://doi.org/10.1016/i.ejrh.2016.05.002

PEREIRA, H.R., MESCHIATTI, M. C., PIRES, R. C. M., BLAIN, G. C. On the performance of three índices of agrément: na easy-to-use-r-code for calculating the willmott indices. Bragantia, v. 77 n. 2, 2018. Disponível em:< https://www.scielo.br/scielo.php?pid=S000687052018000200394\&script=sci_arttext>. Acesso em: 20 jun. 2019. https://doi.org/10.1590/16784499.2017054

PETERNELLI, L.A. Regressão Linear e correção. Viçosa: UFV, 2004. Disponível em:<http://www.dpi.ufv.br/ peternelli/inf162.www.16032004/materiais/CAPITULO9.pdf>. Acesso em: 01 jun. 2019

PONTES, L.M., VIOLA, M. R., SILVA, M. L. N., BISPO, D. F. A., CURI, N. Hydrological Modeling of Tributaries of Cantareira System, Southeast Brazil, with the SWAT model. Revista Brasileira de Engenharia Agrícola e Ambiental, v.36, n.6, 2016. Disponível em:< https://www.scielo.br/scielo.php?pid=S0100-69162016000601037\&script=sci_abstract $>$. Acesso em: 06 jun. 2019. https://doi.org/10.1590/1809-4430-eng.agric.v36n6p1037-1049/2016

RENNÓ, C. D. e SOARES, J. V. Modelos hidrológicos para gestão ambiental. Programa de Ciência e Tecnologia para Gestão de Ecossistemas - Relatório Técnico Parcial. MCT/INPE. São José dos Campos: INPE, 2000. 60p. Relatório.

ROCHA, A. M. Modelagem Hidrossedimentológica da Bacia Hidrográfica do Ribeirão do Pinhal, Limeira/SP caracterizada pela Expansão da Cana-de-Açúcar. Dissertação (Mestrado em Agricultura Tropical e Subtropical). Instituto Agronômico de Campinas, Campinas, 2015.

SANTOS, H. G., JACOMINE, P. K. T., ANJOS, L. H. C., OLIVEIRA, V. A., LUMBRERAS, J. F., COELHO, R. M., ALMEIDA, J. A., ARAÚJO FILHO, J. C., OLIVEIRA, J. B., CUNHA, T. J. F. Sistema Brasileiro de Classificação dos Solos. 3. ed. rev.ampli. Brasília: Embrapa, 353p, 2013.

TUCCI, C. E. M. Hidrologia: ciência e aplicação. 2ed. Porto Alegre: Associação Brasileira de Recursos Hídricos, 1997. https://doi.org/10.21168/rbrh.v2n2.p191-206

Recebido em: 18/05/2020

Aceito para publicação em: 28/09/2020 